\title{
Student perspectives of independent and collaborative learning in a flipped foundational engineering course
}

Pinelopi A. Zaka

University of Canterbury, New Zealand

Wendy H. Fox

University of Waikato, New Zealand

Paul D. Docherty

University of Canterbury, New Zealand

\begin{abstract}
Flipped teaching and learning approaches are being increasingly used in higher education. Some advantages associated with the approach include providing opportunity for selfdirected learning and enhanced collaboration between students. In this study, an implementation of a flipped approach in a first year foundational engineering dynamics course was researched to investigate student views on independent and collaborative learning inherent in flipped learning. Eighteen undergraduate students $(11$ male and 7 female) participated in this qualitative study. The flipped part of the course was designed to include self-paced independent learning and in-class learning, with opportunities to collaborate, ask questions, and work on examples. Data were collected using semistructured interviews. The results of the study indicated that students universally enjoyed learning independently and appreciated the increased collaboration induced by the flipped approach. The flexibility of the approach enabled a range of approaches to independent learning and collaboration, and students were able to find learning styles that suited them. This article concludes with a range of recommendations for practice to further support independent and collaborative learning with the use of flipped approaches.
\end{abstract}

\section{Introduction}

Flipped teaching and learning is an approach that brings the student to the centre of the learning environment. In such classrooms, the student is in more control of their own learning and the teacher's role shifts to knowledge consolidator. In contrast, in traditional approaches the teacher introduces the knowledge directly to the student who must consolidate the knowledge in their own time. King (1993) described this contrast as the teacher being a guide on the side, rather than a sage on the stage. In a flipped classroom, learning occurs both outside and inside the classroom, with the student engaging with the course content in their own time and pace, before the scheduled class time. During class time, the student is able to further develop his/her learning by engaging in activities that require more collaboration, application of knowledge, and use of higher order thinking skills. O'Flaherty and Phillips (2015) define the two stages of flipped learning as follows. During the first stage, the student engages in pre-classroom learning at their own time, place and pace (usually delivered via pre-recorded video lectures, enhanced by readings, simulations and presentations). In the second stage, in-class learning takes place with the student engaging in activities often involving discussions, presentations, role plays, formative assessment and feedback.

Although flipped teaching and learning is developing in tertiary education, the fundamental principles of the approach relating to independent learning, and the shift in the role of both the teacher and the student are not new. What has changed over the last few years though is that the emergence of digital technologies has further enabled teachers to facilitate learning that takes place at students' own time and pace with the use of multimedia learning and teaching tools (Bergman \& Sams, 2014).

The flipped approach is recognised as an effective pedagogy that may facilitate knowledge uptake and retention, rather than knowledge transfer (Mayer, 2002). The flipped classroom approach resonates with Vygotsky's sociocultural learning theory, particularly the concept of the zone of proximal development, where the role of interactions is fundamental in the process of learning (Vygotsky, 1978). In flipped classrooms, learning occurs both independently at the student's own time and collaboratively in scheduled classes (Lavelle, Stimpson, \& Brill, 2013). Learning therefore depends not just on the student's 
own individual efforts and abilities, but also on the type of interactions and support he/she receives from their peers and teacher, especially during in-class learning. Guided participation in sociocultural learning theory and sociocultural conflict theory are also intrinsic within the flipped classroom approach. In flipped classrooms, students are provided with opportunities during the in-class learning to collaborate, support and learn from one another with facilitation and direct engagement from the teacher. It is during these interactions that opportunities for cognitive conflict and cognitive change are likely to occur, as students exchange ideas and stimulate each other's thinking.

Tertiary institutions' uptake of flipped teaching and learning approaches has been impacted by a range of identified advantages. In their literature review on the use of flipped approaches in tertiary education, O'Flaherty and Phillips (2015) found that a range of studies have identified economic benefits of using flipped approaches for institutions facing financial constraints that limit face to face teaching. Other benefits include the opportunity to cover more material over a short period of time and freeing up more time for active learning, collaboration, critical thinking, problem solving, and deeper understanding of the content (Cunningham, 2016; Mason, Shuman, \& Cook, 2013; Yelamarthi \& Drake, 2015).

Cunningham (2016) argues that the non-transience of the learning materials delivered as audio visual resources gives students more control of their learning. In particular, students are able to pause, replay, slow down and speed up the source of content delivery. In their study of undergraduate medical students' experience with flipped learning, McLean, Attardi, Fadden, and Goltzmidt (2016) suggest that flipped approaches have the potential to assist students in developing independent learning strategies. McLean et al. (2016) found that most students realised early on that they had to become more independent to achieve their desired results while undertaking a flipped classroom.

In addition to independent learning, the use of flipped approaches provides additional opportunities for collaboration between students (Lavelle et al., 2013). Foldnes (2016) found that collaborating in a flipped classroom can increase student academic achievement. However, Foldnes further argues that using a flipped approach is not enough to encourage collaborative learning; the lecturer's role in properly implementing a flipped approach with opportunities and encouragement for collaborative learning is critical. Similarly, Chen and Chuang (2016) found that the benefits to learning can be further enhanced with the combined use of flipped and collaborative learning approaches.

Several studies have looked at how flipped classrooms can be designed to support independent and collaborative learning. Video lectures are often used to deliver the course content (Bishop \& Verleger, 2013), incorporating audio narration screen share and/or video stream to provide visual representation of the concepts that are being presented. Where relevant, solving problems might also be demonstrated to students to explain the thought process behind the solution (Mason et al., 2013; Yelamarthi \& Drake, 2015). Some studies have deployed strategies to deliver content that use multiple media, such as short video lectures (10-15 minutes long) and supplemental reading materials (Gilboy, Heinrichs, \& Pazzaglia, 2014). The use of worksheets to scaffold students is also often seen in the literature as a strategy to support students' independent learning (Gilboy et al., 2014). Quizzes that provide instant feedback to the students on their progress are often used to support students during their independent learning (Chen \& Chuang, 2016; Yelamarthi \& Drake, 2015). Quizzes have been used as a means to support collaborative learning as well, by encouraging students to complete them individually first and then as a group (Foldnes, 2016). Group work that is based on authentic tasks is another strategy to support collaborative learning (Chen \& Chuang, 2016). Gilboy et al. (2014) suggest using a few similar active learning strategies throughout the duration of a flipped course, rather than different active learning strategies for each session. In this way students will become familiar with the strategy faster and will be able to focus on the task rather than the process of the strategy.

Although students often have positive attitudes towards the use of technology for learning (Chen, Chen \& Chen, 2015; McNally et al., 2017), student perceptions of the flipped classroom approach vary. McNally et al. (2017) conducted research with 563 higher education students in Australia and found that students can be grouped in two categories based on their preferences with regards to the flipped classroom; the flip endorsers and the flip resisters. The first group typically accept most aspects of the flipped classroom and remain involved and engaged. The second group appears to be more neutral on some aspects of the flipped classroom and less likely to engage in pre-class activities. The study suggested that student maturity, level of study, and gender may affect their perceptions. In particular, mature and female 
students indicated greater acceptance of the flipped approach. In the same study, students whose first language was not English and studied in English tended to prefer the flipped approach, possibly due to the ability to revisit content multiple times. It is not certain whether student perceptions of the flipped classroom are affected by the subject area. In their literature review, O'Flaherty and Phillips (2015) found that the majority of studies reported mostly positive attitudes from students towards the flipped approach, but some studies reported mostly negative perceptions. This may have occurred due to the different subject areas the studies were focusing on, but the authors do not exclude the possibility of the Hawthorne effect (alteration of students' behaviour due to knowledge of being observed). It has been repeatedly reported though that student views of the flipped classroom are affected by its effective implementation by the teacher (Khanova, Roth, Rodgers, \& McLaughlin, 2015; Zhang, Dang, \& Amer, 2016).

Students often value the increased flexibility that flipped classrooms provide to engage with course materials at their own time and pace (Blair, Maharaj, \& Primus, 2016; Hanson, 2016; Love, Hodge, Grandgenett, \& Swift, 2014). They also acknowledge the importance of engaging with the online course materials as part of their pre-class activities (Blair et al., 2016; Nguyen, Yu, Japutra, \& Chen, 2015). In engineering education, students often express positive experiences with flipped approaches, particularly in terms of developing independent learning, problem-solving, critical thinking, and collaborative learning skills (Baytiyeh \& Naja, 2016).

Students' reluctance to engage with flipped learning is often a result of their perception of how learning occurs (Chen, Chen, \& Chen, 2015). Shih and Tsai (2017) found that one of the reasons that students often did not engage with pre-class activities was that they were mostly used to learning in a traditional lecture format. The amount of course materials students have to engage with before the scheduled classes, as well as the level of support from the lecturer were factors that influence student transition from being passive receivers of knowledge to becoming active learners (Shih \& Tsai, 2017).

The literature presents varied results regarding student academic achievement in flipped classrooms. Studies often report that students in flipped classrooms achieve better results (Kerr, 2015; O'Flaherty \& Phillips, 2015; Yelamarthi \& Drake, 2015). However, there are studies showing no significant difference in students' academic achievement when comparing traditional to flipped classrooms (Wilson, 2013), or significant differences in some but not most aspects of the course. For example, Mason et al. (2013) found that the flipped classroom students in an engineering subject had better exam performance on design problems than students that were taught in a traditional classroom. The effect of the flipped classroom on student academic performance remains ambiguous, given the possible publication bias which may occur when studies have negative or ambiguous results (Pigott, Valentine, Polanin, Williams, \& Canada, 2013).

\section{Research questions}

This study investigated two questions on the use of the flipped learning approach in a foundational engineering course:

1. What were the students' views of independent and collaborative learning in flipped learning?

2. What were the advantages and disadvantages of this approach?

\section{Methods}

The findings of this study are part of a wider mixed-method study that assessed the overall effectiveness of the flipped classroom, looking at student academic achievement (using quantitative research methods) and student perspectives of the approach (using qualitative research methods) in a summer course. The quantitative analysis took place at the beginning of the study. The qualitative part of the study followed afterwards with interviews, data analysis, and interpretation. This paper presents an in depth analysis of the qualitative data to determine the students' perceptions of how the teaching approach affected their own independent and collaborative learning.

Participants of this study were students who had taken a foundational engineering mechanics course partially taught with a flipped approach during the summer semesters of 2014 and 2015. The summer semesters had a shorter duration than the other two university semesters and thus, the pace of the course 
was faster. Students were limited to enrolling in a maximum of two summer courses to reduce impact of the increased pace. The 2014 and 2015 cohorts had one lecturer and 54 and 69 students respectively. Nine students from each cohort (18 in total: 11 male and 7 female) agreed to participate in a semi-structured focus group interview with the researchers. Thirteen of these students were recent school leavers and five were mature students. All student participants indicated that this was their first experience with flipped approach to learning.

This study aimed to understand and interpret, rather than generalise student experiences in the flipped classroom through their own perspectives and feelings. The research methodology of this study was informed by the interpretivist paradigm that acknowledges the existence of multiple realities, rather than one objective truth. Knowledge is perceived rather than obtained and the role of the environment/context is very important in constructing meaning (Neuman, 2000).

The semi structured interview format enabled the researchers to ask questions about why, what and how participants engaged with the approach (Taylor \& Bogdan, 1998). The researchers designed open-ended questions and planned the interview schedule to allow for follow-up questions and group discussions where relevant. The interview questions were developed collaboratively by the researchers and were based on the researchers' previous experience investigating student perspectives. The questions investigated aspects such as students perceptions of the course in general, student views of the flipped approach, aspects of the course the students enjoyed the most, aspects they least enjoyed, their perspectives of the lecturer's approach, and their perspectives of their own learning in the flipped classroom. The group format enabled participants to prompt and be prompted by other participants' contributions (Cohen, Manion, \& Morrison, 2001). Eight interviews were carried out in total. Other than two participants, who were interviewed individually due to time constrains, the rest of the participants were interviewed in groups of two or three.

The participants were recruited and interviewed by the first and second author. The third author was the lecturer of the foundational engineering dynamics course and was ethically constrained from taking part in the interview process. The identities of the participants were kept confidential and the third author/lecturer only had access to the de-identified interview transcripts. Ethical consent was given for this study by the University of Canterbury Educational Research Human Ethics Committee. The data was clustered into clear themes relating to independent learning.

After transcribing the interviews, thematic analysis was used to code the transcripts and identify emerging themes. Each participant transcript was analysed by the researchers who came to a consensus on each statement before its contribution to the themes was determined. This way the data was analysed by more than one researcher, to achieve more linkages and alternative interpretations, and the themes were validated after being reviewed by all researchers (Boyatzis, 1998). This paper focuses on two of the most common themes: independent learning and collaborative learning. Other themes included: student empowerment and engagement, student perspectives of teaching, and student perspectives of learning. A more detailed description and discussion on these themes is beyond the scope of this paper and are included in other publications (Docherty, Fox-Turnbull, \& Zaka, 2017).

\section{The flipped classroom}

The course was offered during an 8 week summer semester, was divided into two parts, each taught by a different lecturer. A statics section was taught during the first 4 weeks using a traditional teaching approach. The subsequent dynamics section was offered from weeks 5 to 8 , and was taught using a flipped approach. This research focuses on the flipped dynamics section only. The flipped classroom was designed by the course lecturer in consultation with the university's e-learning support unit. It was based on the following principles: effective use of multimedia with short (up to 30 minutes) clear videos, student support throughout the implementation of the approach, and modification of in-class teaching to provide more opportunities for active and collaborative learning. Such design principles have been reported in the flipped teaching and learning literature (Lo, Hew, \& Chen, 2017). At the beginning of the dynamics section, the lecturer explained to the students that a flipped approach was going to be trialled. The lecturer discussed with the students the way the flip was going to take place, highlighting the two stages of learning: (1) pre-class learning relying on independent and self-directed learning strategies and 
video resources, and (2) in-class learning with discussion, one on one support, independent, and collaborative activities.

After the first week, the lecturer sought informal student feedback which showed that students were enjoying the approach. The lecturer continued with the flipped approach for the duration of the course. Students again provided positive feedback at the end of the course (via the class' regular end of course survey). Therefore, the lecturer used the flipped approach during the second year as well.

To support students' independent learning, the lecture material was delivered using slide presentation software with embedded audio narration and on screen annotations (Figure 1), which were recorded and saved in a video format (recorded lectures). This format of delivery aimed at presenting information to students in different forms (audio and text/illustrations), gradually presenting complex information (e.g., solving problems) while also enabling students to pause, review and/or fast forward the content. The lecturer also provided students with skeleton notes for each recorded lecture, to provide additional scaffolding, as the expectation was that students would add their notes and bring questions and queries to class for discussion. The recorded lectures were approximately 30 minutes each to make it easier for the students to find the time to watch during the day. The university's learning management system was used to share the recorded lectures with the students each week, to avoid information overload while learning independently. This also helped the students focus on their weekly tasks as opposed to providing all content from the beginning of the course. Students were expected to watch two recordings before each scheduled weekly face-to-face session.

Velocity is the rate of change of displacement with respect to a particular direction.

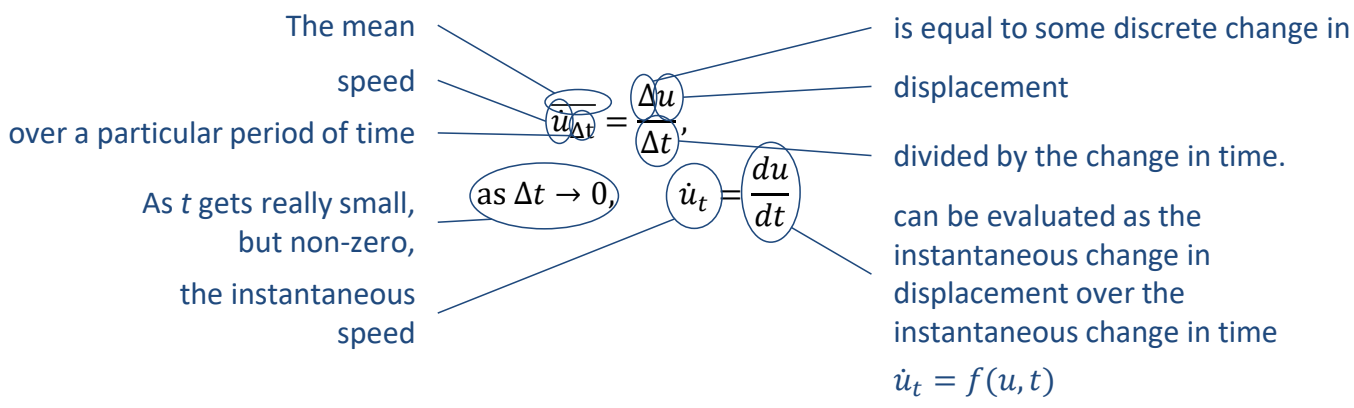

Figure 1. Example slide from lecture videos. The lecturer added notes in blue as content was narrated.

There were three face-to-face workshop sessions each week. The sessions involved answering student questions and providing a collaborative environment for students to work on examples and apply their knowledge to real world engineering applications. The lecturer also expected to provide individualised assistance to students during these scheduled sessions. During the first 30 to 40 minutes of each session, the lecturer encouraged students to share their questions in class about the content covered in the recorded lectures. Responses to these questions were intended to cover conceptual gaps for a number of participants in the cohort. In the second part of each scheduled session (70 to 80 minutes) the students utilised their new knowledge to solve four or five example problems. Students were strongly encouraged to work on the problems in groups of three to eight. To maximise student engagement, problems were generally drawn from engineering practice or sporting phenomena. Specific examples included drawing free body diagrams of paragliders in flight and numerical kinetic analysis of spinning toddlers carrying weights in their hands. Approximately 30 to $50 \%$ of the students attended each scheduled session. Table 1 summarises the characteristics of the flipped approach for each session used in the foundational engineering dynamics course. 
Table 1

Characteristics of the flipped foundational engineering dynamics class

\begin{tabular}{|l|l|}
\hline \multicolumn{2}{|l|}{ Flipped foundational engineering dynamics } \\
\hline Pre-class learning & \multicolumn{2}{l|}{ In-class learning } \\
\hline$\bullet \quad \begin{array}{l}\text { learning management system (Moodle) } \\
-\quad 2 \times 30 \text { minute recorded lectures before each } \\
\text { face-to-face workshop session (6 per week in } \\
\text { total) } \\
\text { skeleton notes } \\
\text { student-led pace of delivery }\end{array}$ & $\begin{array}{l}\text { questions and answers } \\
\text { example problems } \\
\text { independent and collaborative work } \\
\text { lecturer as a facilitator } \\
\text { one to one support }\end{array}$ \\
\hline
\end{tabular}

The statics section of the course was taught using traditional lectures and formed $50 \%$ of the course grade. Only the dynamics section used the flipped classroom and made up the remaining $50 \%$ of the course grade. In the dynamics section, formative assessment was undertaken via online quizzes $(10 \%$ course grade) and summative assessment used a typical exam (40\% of course grade). The dynamics exam required students to use kinematics, kinetics, and energy methods to analyse three physical systems of complex motion. Students would have to evaluate symbolic expressions or numeric values for a variety of system dynamics in multipart questions that generally became more difficult across sub-questions. The lecturer set the examination questions that were verified as appropriate by a colleague, and marked the exam.

\section{Results}

The study identified seven sub-themes relating to independent and collaborative learning; which are discussed in the following sections. There were no distinct discernible differences in student answers between the two cohorts. An overview of these themes and subthemes is listed:

- Independent learning

○ flexible learning at students' own time and pace

- shifting the responsibility from the teacher to the student

o challenges in learning independently

- strategies deployed by the students while learning independently

$\circ \quad$ in class reassurance and support - motivation for independent learning

- Collaborative learning

- pre-class learning with other people

$\circ$ in-class peer support and collaboration

\section{Student perspectives of independent learning}

Flexible learning at students' own time and pace

After the introduction to the flipped classroom provided by the lecturer, the majority of the students appreciated the flexibility that they were potentially going to be provided with: "When I heard of the flipped classroom I was pretty excited because for me it means when I need to do things and I can't be in class it's not a problem. I can do things in my own time" (Student H).

After experiencing the approach, one of the benefits that the majority of the students reported was the flexibility it provided them with and the ability to control the pace of their learning for the first part of the flip (when learning independently). Students shared that they enjoyed the fact that they could view the lecture material at their own time and pace, which was something that they did not have the chance to do in a real time lecture: 
I really enjoyed it [as] I was able to pause it if I didn't know something, pause it, google it, pause it, do something else, come back to it, and it didn't feel like you had to stay there the whole time. (Student I)

It was really good and it meant that you watched the lectures in your own time and you could catch up when you needed to catch up. (Student N)

One of the students explained that this ability to pause, rewind and fast forward the lecture material was what enhanced his understanding, as he was able to focus more on the content, rather than on note taking:

When you're taking notes in real time lectures you focus more on taking notes and you don't have time to digest the information; [in the flipped classroom] they (students) could pause and think about what they just wrote and the content sunk in better. (Student $\mathrm{O}$ )

Shifting the responsibility from the teacher to the student

While students had the flexibility to watch the lectures at their own time and pace, they recognised the need to manage their time effectively in order to be successful: "Then you can still stop and pause, but you have to watch that lecture that day ... So therefore, you're not thinking, oh I can just watch it anytime and then leave everything before the exams" (Student K).

One of the students added that he personally had the required self-control. This was a mature student who commented that did not have the same level of self-control when he was the same age as the majority of the other students in his cohort:

In terms of motivation, it puts the responsibility on yourself. So, we're adults; you're here to learn, or you're here for a specific reason. You shouldn't need motivation. Whether it was hot outside or cold outside, you shouldn't need motivation to watch the video. That's how I found it ... I wouldn't have been able to do it when I was 18 . There wouldn't have been a chance. (Student P)

Quantifying student engagement time with the course content was beyond the scope of this study. However, a number of students commented on the shift they observed in their understanding of responsibility for learning. Regardless of the choices students made (whether to engage in independent learning before the scheduled class time or not), students explained that the flexibility that the flipped classroom provided them with was also making them more responsible for their learning. This was an interesting finding, given that the majority of participants were first year undergraduate students who had just finished secondary school the year before their summer course:

The flipped classroom is very self-directed learning. You have to sit down at home, you have to watch the lecture, you have to take notes by yourself, there is no one telling you that you have to be there in class, you can do whatever you want, you don't have to go to the tutorial, you go there if you want help, if you want to push yourself and you want to learn more. (Student M)

Sometimes you don't watch them (the lectures) and that happened to me a few times and then I struggled to catch up ... in the tutorials it was hard to understand what they were talking about. But that is your own fault, you just kind of get used to it - get used to watching and then going. (Student O)

\section{Challenges in learning independently}

A number of students shared that managing their own learning was not an easy task. For the majority of them this was a new approach that they were experiencing for the first time:

The moment you missed one (recorded lecture) and you go to the tutorial and have no idea what's going on and then you kind of waste that tutorial but you can't fully engage in it so you have to re-watch it that night to catch-up. (Student $O$ )

At some point I was struggling to keep up with watching the videos ... also a bad thing because you spent a lot more time going over it. (Student L) 
One of the students that was also working full time at the time of their study, mentioned that learning independently was even more challenging. This was due to the limited time the student had to watch the lectures and due to the fast pace of the course (being offered in the summer semester):

For me it was at least three hours in the evening after I came home from work ... you finish that and you are exhausted ... Too many new facts per day which my brain has to go through ... I do believe it was a negative experience for me because of the time frame, it was very condensed. (Student A)

Other students found that learning independently was challenging due to the lack of reassurance whether they had successfully understood the content before going to the scheduled face-to-face session. Some of the students mentioned that this was even more challenging because at times there were minor transcription errors in the recorded lectures, resulting in them having to spend more time to understand certain areas: "I wouldn't understand things and then you'd get to class and (the lecturer would say): 'Oh yeah, that was a mistake'. So it was like I wasn't sure sometimes”' (Student B).

Students suggested that undertaking more than one or two courses using a flipped approach would be very arduous, especially for those unfamiliar with independent learning. The majority of the students commented that their success was also a result of doing a summer course and not having other courses during the same period. The students therefore suggested avoiding the taking of more than one or two flipped approach courses in any one semester, especially for people new to learning independently: "I don't know if I'd be able to do all of them (flipped courses) just because of the fact that they'd take too much time" (Student F).

Strategies deployed by students while learning independently

Many of the students explained that they used strategies for learning independently regardless of the approach being used in the classroom. Some stated that even with traditional learning approaches they often searched for and used additional support material to strengthen their understanding of the content (whether delivered in real time or asynchronously): " 25 years ago, you had to rely on a tutor or get some old textbooks which you read and don't understand. Now days you just google it you find about $10-20$ versions. You go to YouTube, same thing" (Student A).

Online resources such as Khan Academy and YouTube videos were mentioned numerous times by the students as support material that they searched for and used on an 'as and when needed' basis. The flipped approach ultimately enabled students to seek and benefit from additional learning resources to use as part of their independent learning strategies:

I really enjoyed it [because] I was able to pause it if I didn't know something, pause it, google it, pause it to do something else, come back to it and it didn't feel like you had to stay there the whole time. (Student I)

That was probably why I liked the flipped classroom so much; just because I used tools like Khan Academy videos and stuff anyway. (Student B)

One of the students provided a specific example of using additional resources to supplement the recorded lectures: "I remember one part I just couldn't get it, and it was a relatively big part. I watched this minutelong video, and they just explained it so easily, and it's like, oh this is simple!" (Student C).

Another strategy the students shared to reduce the challenges of learning independently was to try to keep up with the content. Delaying engagement with the pre-recorded lectures until just prior to the exam was identified as a risk by some students. In particular, such delays would mitigate the benefits of face-to-face individualised support from the lecturer: "I think I would have got a deeper understanding if I (had) watched it all beforehand" (Student M).

In addition, students shared that because of the fast pace of the course, it was very easy to lose track of what was learnt and when. Some students identified that going to the face-to-face session prepared, with a list of written questions and notes was very useful, as they were able to maximise their time with the 
lecturer: "(I recommend) Maybe write a list of questions out and then you know what you will ask at the next tutorial. Just keeping up-to-date" (Student N).

In-class reassurance and support - motivation for independent learning

Despite these challenges, the majority of the students reported that learning independently was a positive experience. This was mainly because of the time they were getting with the lecturer, rather than the fact that they could self-direct their learning. The scheduled sessions were seen as an opportunity for students to ask their questions, strengthen their understanding of the content and extend their knowledge. For most of the students, this was the most enjoyable and valuable outcome of the flipped classroom:

I think probably it went a bit better for me doing flipped instead of the traditional approach. Personally for me, for dynamics I needed more tutor/lecturer time, like engaging and asking questions about things I got stuck on. So that helped me really. (Student N)

[It was] easier to get that one-on-one time, easier to get the help you needed ... You could have lots of one-on-one with the lecturer ... a lot of time these days you don't get to interact with the lecturers at all. (Student M)

I really liked we had tutorials every day after you watched the videos, so I would have some questions I wanted to know about so I could ask the teacher. (Student F)

The students acknowledged that by engaging with lecture material prior to the session, there was more time available in the face-to-face session to focus on individualised support. Therefore, this further encouraged some to learn independently and bring their questions and notes to the scheduled sessions: "It was ... very easy to go away and look at it and then come to class with your questions already done and (say) these are my questions, how's this done? Or why did you do it like that?” (Student I).

Some of the students added that it was not only the flipped format that freed up more time during the scheduled sessions for one-on-one support; it was also the lecturer's supportive and positive attitude that motivated them: "I found (him to be) an excellent teacher and also I really engaged with him as a lecturer and teacher. It was great. I found it really engaging” (Student G).

One of the students explained that the combination of independent learning and support they were getting during the scheduled sessions, enhanced their understanding of the content and therefore their motivation to learn and achievement: "I feel like it did (improve my grades) because I was enjoying the way I was taught and the fact that I did the initial preparation at home before I came to Uni" (Student F).

\section{Student perspectives of collaborative learning}

While introducing the flipped approach to the cohort, the lecturer recommended that students work collaboratively throughout the course. In particular, students were encouraged to form study groups or pairs and support one another during their independent study, as well as work together in class. Most of the interviewed students shared that they did collaborate with their peers throughout the duration of the flipped course. The following findings outline student experience with collaborative learning during both stages of the flipped approach (pre and in-class learning).

\section{Pre-class learning with other people}

About half of the student participants reported that they were studying and preparing for the scheduled classes with either a friend or a group of friends. Students had different ways of studying in their group. In particular, one of the students mentioned that they were watching the pre-recorded lectures together with their friend, pausing and discussing concepts that needed further clarification:

I was doing it with a very good friend of mine. We spent a lot of time, we'd watch them together and we'd hit a problem and we'd both work through what (the lecturer) was trying to get towards, and the next day we'd be very confident in what we'd got. (Student C)

Some of the students that formed a study group were in the same place when studying but were not viewing the lectures together. These students were working independently up to a point and coming back together as a group to discuss certain concepts: "me [sic] and [another student] ... were doing summer 
school together. So we would just get a room in the library and both watch our own videos separately, but then we would ask each other [for] help, which I thought worked very well” (Student N).

One of the students mentioned that studying with other people was a useful strategy. The student's study group remained engaged with the course material and avoided getting side-tracked while independently watching the lectures.

Sometimes we'd be in a discussion room in the library, but we'd all just - even just on a silent floor, we'd be with people but we wouldn't usually interact. It was just more to like so if you were with other people, you're not going to go off and start playing a game or watching Game of Thrones. (Student C)

Other students preferred to study independently from their own location and not form study groups. These students commented that working independently at their own pace and chosen location was a preferable way of studying.

I think it might be good, but [what happens] let's say for example if I don't understand one part and then I wanted to pause the video but he understands, but I don't know if that creates a conflict or let's say I understood that part but he pauses? (Student E)

I feel like for me I prefer watching on my own because if I was watching with somebody else and I did spend more time than being able to pass something very quickly; but for me I enjoyed doing it at my own pace because I could skip the things I knew I had learned before. (Student G)

Other students were unable to participate in study groups due to work or other commitments that were preventing them from studying during popular studying times: "I was working as well, and I was working a lot of hours because of Christmas rushing and sort of things, so I would probably have not been able to watch with someone or skip it" (Student F).

Some students indicated that they preferred studying independently. However, even these students mentioned that they engaged in collaboration with their peers via online messaging and text, thus, reporting a benefit from peer support while engaging with video lectures.

Me and my friend we would send each other messages and ask questions; so we may not be doing [study] at the same time but [we would send each other] those kinds of quick questions that you would usually ask your neighbour in a lecture theatre, we just did [that] online, because we would still go in different pace. (Student $\mathrm{H}$ )

One of the students mentioned that future iterations of the approach should have an online class forum for quick questions and peer support when watching the lectures. They felt that this forum would be particularly beneficial for students that study at their own time and pace: "It's like an addition; a forum where you can post questions, and the lecturer or other students can answer it" (Student C).

\section{In-class peer support and collaboration}

As mentioned previously, the lecturer had structured the scheduled sessions such that students were strongly encouraged to work in groups. Most interviewed students reported that they did work in a group during the scheduled sessions and that this strategy enabled them to strengthen their understanding of the course content:

I definitely feel that working with a partner or small group really helped. As soon as I hit a roadblock or something that I didn't understand, I could bounce ideas off [student name] and he could do the same with me. (Student D)

There was a group of about five of us and we just worked questions together and if we needed help he (the lecturer) could come and help us. (Student I)

Some students explained that being part of a group was a motivating factor to watch the lectures and come to class prepared: "It's motivation for me to come and do my problems and do the work and 
motivated me to go knowing that I was coming back to the rest of the group and I could be prepared and continue" (Student F).

In addition to the individual support from the lecturer, some students were motivated to attend the tutorials for the peer support they knew they would get from other students in their group: "Knowing your friends are gonna be there and you gonna discuss things together, you are going to get questions answered and you are going to get something useful out of it" (Student I).

One of the students mentioned that in classes with larger student numbers, individual support from the lecturer is not very frequent. Therefore working collaboratively and getting support from peers is another way to assist student learning:

I think that's also the best way with the lack of tutors; you can't sit by yourself and expect the tutor to come and help you. If you're with a group, everyone can kind of work on a separate problem or something and you all work through it a bit more. (Student J)

\section{Discussion}

Student experiences of independent and collaborative learning in the flipped foundational engineering dynamics classroom varied. Most student participants enjoyed this approach, but some preferred traditional real-time lecturer delivered content. The results of this study give rise to further discussion and recommendations relating to strategies to support students' independent and collaborative learning during both stages of the flipped approach: before and during the scheduled sessions.

Overall, students appreciated the flexibility of learning at their own time and pace. Positive student attitudes towards the increased flexibility and reviewability of the material that the flipped approach offers has been consistently reported by research on flipped teaching and learning (Gilboy et al., 2014; Khanova et al., 2015; Koo et al., 2016). In this study, students shared that the reviewability of the material enabled them to control the pace of their learning. Students were able to pause or accelerate the recorded lectures to suit their ability to learn material. Thus, the course content delivery rate could be modulated according to individual student needs. In contrast, in a traditional lecture, the lecturer must set the pace they determine to be appropriate for the typical student. Atypical students either have poor efficiency of learning or fail to grasp the concepts delivered in the lecture. Hence, the flipped classroom offers a unique opportunity to address the educational needs of the student that needs more time to engage with the course material, the student who is a fast learner, and the student who wishes to extend their understanding with more in-depth learning. Vygotsky's sociocultural theory (Vygotsky, 1978) also supports a student-centred self-paced approach to enable opportunities for all students to reach their maximum potential.

For the majority of the students, learning in a flipped classroom was a new approach. The teaching style they were more familiar with before experiencing the flipped classroom was the traditional model, where the lecturer was at the centre of the instruction. The students' contribution was to attend lectures and undertake tasks as prompted. In contrast, the flipped classroom placed responsibility on the individual. Similar to this study, Phillips and Trainor (2014) found that although millennial students prefer learningby-doing in tertiary education, the majority of them are mostly exposed to lecture-based learning. Students in this study shared that the flexibility of the flipped classroom meant that the responsibility for learning was shifted from the teacher to the learner. This aligns with Bergman and Sams (2014) who also state that students appreciated the student-centred and self-paced approach. Regardless of the choices students made on the extent of their engagement with independent learning, they did acknowledge that it was their responsibility to engage with the lectures in their own time and ensure that they had developed their understanding of the content prior to the scheduled classes. This was an important outcome of the flipped approach in this study; assuming personal responsibility indicates that students begun to further develop their metacognitive skills, which in turn are important to enable reflective thinking and lifelong learning (Devlin, 2002).

One of the challenges that students faced when learning independently was relating to their ability to manage their time and workload and keep up with the pace of the course in addition to other responsibilities they may have had (e.g., work or family commitments). These findings further support the 
importance of managing student expectations with regards to the requirements and possible challenges of a flipped classroom approach as suggested by Green and Schlairet (2017). Students in this study also shared their concerns of managing their workload if more than one course used a flipped classroom approach. This aligns with Khanova et al. (2015) who suggest that when students undertake multiple classes that utilise the flipped model, a series of relatively small problems can compound into major barriers to success. They recommended that students be advised of this risk when multiple classes use the flipped learning approach. Such a recommendation implies further collaboration between staff preparing to teach flipped courses and might be easier to apply in courses that are part of the same curriculum.

A number of students shared that the limited instant reassurance from the lecturer when independently watching the recorded lectures was an additional challenge. In a traditional lecture, students would usually be able to ask questions on an as and when needed basis. Such questions could be addressed to the lecturer or even their peers. Other times, lecturers prefer to keep questions for the end of the session. Some students shared that they used peer support when learning independently in order to reassure one another that they were on the right track. In a flipped classroom, the lack of direct reassurance could be addressed with other strategies; these may include online forums or chat rooms for students to post and even answer other students' questions. The value of online forums and discussions in supporting student learning has been extensively reported by the literature (Andersen, 2009; Cheng, Paré, Collimore, \& Joordens, 2011; Ioannou, Brown, \& Artino, 2015; Ko \& Rossen, 2010). Additional opportunities to discuss questions with the lecturer and other students may increase students' ability to solve problems (Reinert, Vollmann, Heyder, \& Krautschneider, 2014). Providing these opportunities before the scheduled classes via a platform that is accessible by the lecturer may also assist the lecturer in preparing for the scheduled session, since they will know before the session what areas students may require further support on. An example of a platform designed to assist students' help-seeking in a flipped classroom was described by Er, Kopcha, Orey, and Dustman (2015), which is based on four principles; (1) addressing students' privacy, (2) increasing awareness of teacher support, (3) promoting observability, and (4) social support.

The students in the study deployed a range of strategies when learning independently. As students were discussing their transition to becoming more independent learners, the majority of them noted that they often searched for additional support material for the recorded lectures that they were watching. This enabled them to enhance their understanding of the lecture content. Other strategies that the students shared to assist in flipped learning included keeping up with the content and going to class with a set of notes that were taken while watching the recordings. Students must be given enough time to adequately engage with the course content. This has previously been identified as an important design principle of flipped classrooms by Kim, Kim, Khera, and Getman (2014), who based their design principles on data collected from university students' experiences of three flipped classrooms.

Students noted that having confidence that their questions would be answered in the scheduled classes and that they were able to get one-on-one support and reassurance in class motivated them during their independent study. Some mentioned the positive impact of the lecturer's enthusiasm on their willingness to prepare properly for the scheduled sessions. Class size was mentioned by the students as an important factor that enabled the lecturer to provide them with individual support, as the lecturer estimated that the scheduled sessions approximately had a 30:1 student teacher ratio (depending on attendance rate). This study supports findings reported from Kerr's (2015) literature review on flipped classrooms in engineering education, suggesting that flipped classrooms may potentially be more successful when implemented in smaller size classes. However, as Kerr argues, given that not all studies in their review reported class size, further research on the effect of class size on flipped classrooms is necessary in order to indicate effective strategies for successful implementation of flipped approaches.

The lecturer in this study ensured that students were provided with multiple opportunities to collaborate and encouraged collaboration on many occasions. Students were encouraged by the lecturer to study with a partner or group of people in order to support one another. Most of the students who were interviewed commented that they followed this recommendation. Their level of collaboration varied; some were more comfortable to watch the recorded lectures together or watch independently, but in the same room with their peers. Others preferred to study independently at their own time and collaborate with their peers on an as-and-when-needed basis. Regardless of how students decided to collaborate with one another, it appears they all benefited from peer support before the scheduled classes. Students in this study also 
reported that they benefited from the opportunities provided to work as a group during the scheduled sessions. The lecturer implemented activities that strongly encouraged group work. Some of the students mentioned they used the same in-class groups during their independent study to support one another. Using a flipped approach does not necessarily mean that students will collaborate with one another, as flipped classrooms may be designed to rely mostly on students' own independent study (Foldnes, 2016). The benefits of collaboration in flipped learning have been associated to positive learning experiences from the students, as well as increased academic achievement (Chen \& Chuang, 2016; Foldnes, 2016). Encouraging student collaboration in flipped classrooms is achieved with carefully designed courses that incorporate group work during the scheduled classes. Students should also be made aware of the value of forming learning groups to enhance learning before scheduled classes. It is suggested that the formation of such groups could be further encouraged with the use of online collaboration tools provided by the lecturer or set up by the students themselves. However, while technology can be used to assist student collaboration, it cannot enforce collaboration or guarantee improved learning outcomes (Marra, Steege, Tsai, \& Tang, 2016). This further highlights the importance of skilful combination of technological, pedagogical, and content knowledge for effective implementation of technology in teaching (Koehler, Mishra, \& Cain, 2013).

It is evident that the flipped approach has the potential to offer a range of benefits to student learning if implemented effectively. Furthermore, student readiness to adapt to non-traditional self-driven learning and collaboration leads to the success of the flipped classroom. This research infers that teacher training for the implementation of flipped classrooms should specifically emphasise the importance of setting up an environment that enables collaboration and to assume that students are naïve to the potential benefits and risks of this teaching approach. Our research has shown that students valued both the independent learning and collaborative learning that the flipped classroom allows. Furthermore, this study encourages thorough student preparation for successful participation in the teaching approach. In particular, students must be informed of the relative freedom of self-driven learning and warned about the discipline required to stay engaged with the course content. Students should also be encouraged to engage in collaborative learning.

\section{Limitations and future work}

The findings of this study are relevant to medium-sized (50 to 80 students) foundational engineering classes in New Zealand tertiary environments and are likely to remain pertinent in similar classes. However, prospective analysis is necessary to determine the efficacy of the methodology in different classes, cultures, or content level. For example, it would be interesting to observe how flipping larger classes to teach similar content may affect students' independent and collaborative learning practices and perceptions, especially given the importance of peer to peer and lecturer support that students mentioned in this study. For technical subjects where understanding is generally binary, rather than developed via practice, discussing the optimal solution with colleagues can lead to enhanced learning. Hence, the collaborative environment may enable enhanced learning as students must verify the correct view amongst a number of candidate opinions held by the group (Doise \& Mugny 1984). Comparative research on students' perspectives of independent and collaborative learning in flipped classrooms for technical subjects and flipped classrooms for subjects where knowledge is less binary, might yield different results in terms of students' perceptions of independent and collaborative learning. It is also important to determine how students' cultural context affects their views of flipped learning, especially in terms of their expectations and dispositions regarding independent learning and collaboration.

This analysis utilised semi-structured interviews with voluntary student recruitment via email. While this methodology enabled relatively easy access to the views of students, it may have limited access to the views of certain subsets of students. In particular, very shy students, or those who failed the class, and discontinued monitoring their email accounts would not be included in the analysis. This selection bias may have caused the high acceptability of collaboration seen in this study. Future research may seek to include more of these subsets of students to ensure that the views of the full cohort are gathered.

The findings of this research and other research in the field have indicated that the flipped classroom is an efficient and effective methodology for tertiary education. Hence it is logical that the approach is more widely used. This growth must be monitored to ensure that the findings associated with early adoptions of the methodology reflect the outcomes of its general implementation. 


\section{Conclusions}

This paper presents research that looked at student perspectives of a particular flipped classroom in a first year engineering dynamics course at a New Zealand university. The findings in this paper focus on independent and collaborative learning in the flipped classroom and were informed by the student perspectives of the approach captured in focus group interviews.

While engaging with pre-class learning, the students enjoyed the student-centred and self-paced approach that the flipped classroom provided them to study independently at their own time and pace. All student participants acknowledged the importance of time-management and organisation in order to succeed in the flipped classroom. This was a considerable challenge that students reported, as they had not experienced a flipped classroom before. Some also reported that they needed more feedback and reassurance while learning independently. However, knowing that the lecturer was available for one-onone support during the scheduled sessions was an important motivating factor for student participants to engage with independent learning before going to class. Students developed and used their own strategies to self-direct their learning, which often included searching and finding additional resources to enhance their understanding of the lecture content, making sure that they remained on track each week, going to class prepared with a set of notes ready to ask questions and forming study groups. After strong encouragement, a number of students engaged in collaboration with their peers before and during the scheduled classes. Student support from their peers was either face-to-face while studying together or online via messaging using their own social platforms.

The findings of this study illustrate the importance of effective course design to support students throughout their learning in a flipped classroom. Such course design needs to take into account students' extended needs for support from the lecturer and their peers, during both phases of the flipped classroom.

\section{Acknowledgements}

The authors would like to express their gratitude to Ako Aotearoa - the New Zealand National Centre for Tertiary Teaching Excellence, the University of Canterbury Educational Research Human Ethics Committee, as well as the University of Canterbury Research Support team for their guidance and support throughout this project.

\section{References}

Andersen, M. A. (2009). Asynchronous discussion forums: Success factors, outcomes, assessments, and limitations. Educational Technology and Society, 12(1), 249-257.

Baytiyeh, H., \& Naja, M. K. (2016). Students' perceptions of the flipped classroom model in an engineering course: A case study. European Journal of Engineering Education, 42(6), 1048-14. https://doi.org/10.1080/03043797.2016.1252905

Bergman, J., \& Sams, A. (2014). Flipped learning: Gateway to student engagement. Washington, DC: International Society for Technology in Education.

Bishop, J. L., \& Verleger, M. A. (2013, June). The flipped classroom: A survey of the research. Paper presented at the ASEE Annual Conference and Exposition, Atlanta, GA.

Blair, E., Maharaj, C., \& Primus, S. (2016). Performance and perception in the flipped classroom. Education and Information Technologies, 21(6), 1465-1482. https://doi.org/10.1007/s10639-0159393-5

Boyatzis, R. E. (1998). The flipped classroom: A survey of the research. Paper presented at the ASEE Annual Conference and Exposition, Atlanta, GA.

Chen, K., \& Chuang, K. (2016). Building a cooperative learning environment in a flipped classroom. Academy of Educational Leadership Journal, 20(2), 8-15.

Chen, L., Chen, T., \& Chen, N. (2015). Students' perspectives of using cooperative learning in a flipped statistics classroom. Australasian Journal of Educational Technology, 31(6), 621-640.

Cheng, C. K., Paré, D. E., Collimore, L., \& Joordens, S. (2011). Assessing the effectiveness of a voluntary online discussion forum on improving students' course performance. Computers \& Education, 56(1), 253-261. https://doi.org/10.1016/j.compedu.2010.07.024 
Cohen, L., Manion, L., \& Morrison, K. (2001). Research methods in education (5th ed.). London: Routledge Falmer. http://dx.doi.org/10.4324/9780203224342

Cunningham, U. (2016). Language pedagogy and non-transience in the flipped classroom. Journal of Open Flexible and Distance Learning, 20(1), 44-58.

Devlin, M. (2002). Taking responsibility for learning isn't everything: A case for developing tertiary students' conceptions of learning. Teaching in Higher Education, 7(2), 125-138. https://doi.org/10.1080/13562510220124231

Docherty, P. D., Fox-Turnbull, W. H., \& Zaka, P. A. (2017). Assessing the effectiveness of a flipped classroom in foundation engineering. Retrieved from: https://ako.ac.nz/assets/Knowledgecentre/RHPF-s-1605-Assessing-the-effectiveness-of-a-flipped-classroom-in-foundationengineering/32484f87ef/RESEARCH-REPORT-Assessing-the-Effectiveness-of-a-FlippedClassroom.pdf

Doise, W., \& Mugny, G. (1984). The social development of the intellect. International series in experimentalsocial psychology. Oxford: Pergamon Press.

Er, E., Kopcha, T., Orey, M., \& Dustman, W. (2015). Exploring college students' online help-seeking behavior in a flipped classroom with a web-based help-seeking tool. Australasian Journal of Educational Technology, 31(5), 537-555.

Foldnes, N. (2016). The flipped classroom and cooperative learning: Evidence from a randomised experiment. Active Learning in Higher Education, 17(1), 39-49. https://doi.org/10.1177/1469787415616726

Gilboy, M. B., Heinrichs, S., \& Pazzaglia, G. (2014). Enhancing student engagement using the flipped classroom. Journal of Nutrition Education and Behavior, 47(1), 109-114. https://doi.org/10.1016/j.jneb.2014.08.008

Green, R. D., \& Schlairet, M. C. (2017). Moving toward heutagogical learning: Illuminating undergraduate nursing students' experiences in a flipped classroom. Nurse Education Today, 49, 122128. https://doi.org/10.1016/j.nedt.2016.11.016

Hanson, J. (2016). Surveying the experiences and perceptions of undergraduate nursing students of a flipped classroom approach to increase understanding of drug science and its application to clinical practice. Nurse Education in Practice 16(1), 79-85. https://doi.org/10.1016/j.nepr.2015.09.001

Ioannou, A., Brown, S., \& Artino, A. (2015). Wikis and forums for collaborative problem-based activity: A systematic comparison of learners' interactions. Internet and Higher Education, 24, 35-45. https://doi.org/10.1016/j.iheduc.2014.09.001

Kerr, B. (2015, September). The flipped classroom in engineering education: A survey of the research. Paper presented at the 18th International Conference on Interactive Collaborative Learning, Florence. https://doi.org/10.1109/ICL.2015.7318133

Khanova, J., Roth, M. T., Rodgers, J. E., \& McLaughlin, J. E. (2015). Student experiences across multiple flipped courses in a single curriculum. Medical Education, 49(10), 1038-1048. https://doi.org/10.1111/medu.12807

Kim, M., Kim, S., Khera, O., \& Getman, J. (2014). The experience of three flipped classrooms in an urban university: An exploration of design principles. Internet and Higher Education, 22, 37-50. https://doi.org/10.1016/j.iheduc.2014.04.003

King, A. (1993). From sage on the stage to guide on the side. College Teaching, 41(1), 30-35. https://doi.org/10.1080/87567555.1993.9926781

Ko, S. S., \& Rossen, S. (2010). Teaching online: A practical guide (3rd ed.). New York, NY: Routledge.

Koehler, M., Mishra, P., \& Cain, W. (2013). What is technological pedagogical content knowledge (TPACK)? The Journal of Education, 193(3), 13-19. https://doi.org/10.1177/002205741319300303

Koo, C. L., Demps, E. L., Farris, C., Bowman, J. D., Panahi, L., \& Boyle, P. (2016). Impact of flipped classroom design on student performance and perceptions in a pharmacotherapy course. American Journal of Pharmaceutical Education, 80(2), 1-9. https://doi.org/10.5688/ajpe80233

Lavelle, J. P., Stimpson, M. T., \& Brill, E. D. (2013). Flipped out engineering economy: Converting a traditional class to an inverted model. In A. Krishnamurthy, \& W. K. V Chan (Eds.), Proceedings of the 2013 Industrial Systems Engineering Research Conference (pp. 397-407). Puerto Rico: HighBeam Research. https://doi.org/10.1111/bjet.12548

Lo, C., Hew, K., \& Chen, G. (2017). Toward a set of design principles for mathematics flipped classrooms: A synthesis of research in mathematics education. Educational Research Review, 22, 5073. https://doi.org/10.1016/j.edurev.2017.08.002 
Love, B., Hodge, A., Grandgenett, N., \& Swift, A. W. (2014). Student learning and perceptions in a flipped linear algebra course. International Journal of Mathematical Education in Science and Technology, 45(3), 317-324. https://doi.org/10.1080/0020739X.2013.822582

Marra, R. M., Steege, L., Tsai, C. L., \& Tang, N. E. (2016). Beyond "group work": An integrated approach to support collaboration in engineering education. International Journal of STEM Education, 3(17), 1-15. https://doi.org/10.1186/s40594-016-0050-3

Mason, G. S., Shuman, T. R., \& Cook, K. E. (2013). Comparing the effectiveness of an inverted classroom to a traditional classroom in an upper-division engineering course. IEEE Transactions on Education, 56(4), 430-435. https://doi.org/10.1109/TE.2013.2249066

Mayer, R. E. (2002). Rote versus meaningful learning. Theory into Practice, 41(4), 226-232. https://doi.org/10.1207/s15430421tip4104_4

McLean, S., Attardi, S., Faden, L., \& Goldszmidt, M. (2016). Flipped classrooms and student learning: Not just surface gains. Advances in Physiology Education, 40(1), 47-55. https://doi.org/10.1152/advan.00098.2015

McNally, B., Chipperfield, J., Dorsett, P., Del Fabbro, L., Frommolt, V., Goetz, S., \& Rung, A. (2017). Flipped classroom experiences: Student preferences and flip strategy in a higher education context. Higher Education, 73(2), 281-298. https://doi.org/10.1007/s10734-016-0014-Z

Neuman, L. W. (2000). Social research methods: Qualitative and quantitative approaches (4th ed.). Needham Heights, MA: Allyn and Bacon.

Nguyen, B., Yu, X., Japutra, A., \& Chen, C-H. S. (2015). Reverse teaching: Exploring student perceptions of "flip teaching". Active Learning in Higher Education, 17(1), 51-61. https://doi.org/10.1177/1469787415616727

O'Flaherty, J. \& Phillips, C. (2015). The use of flipped classrooms in higher education: A scoping review. The Internet and Higher Education, 25(4), 85-95. https://doi.org/10.1016/j.iheduc.2015.02.002

Phillips, C. R., \& Trainor, J. E. (2014). Millennial students and the flipped classroom. Journal of Business and Educational Leadership, 5(1), 102-112.

Pigott, T. D., Valentine, J. C., Polanin, J. R., Williams, R. T., \& Canada, D. D. (2013). Outcomereporting bias in education research. Educational Researcher, 42(8), 424-432. https://doi.org/10.3102/0013189X13507104

Reinert, A., Vollmann, N., Heyder, M., \& Krautschneider, W. (2014). New teaching approaches and student motivation lead to documented gains in engineering education. Proceedings of the IEEE Frontiers of Education Conference, Madrid, 1-4. https://doi.org/10.1109/FIE.2014.7044398

Shih, W.L., \& Tsai, C.Y. (2017). Students' perception of a flipped classroom approach to facilitating online project-based learning in marketing research courses. Australasian Journal of Educational Technology, 33(5), 32-49. https://doi.org/10.14742/ajet.2884

Taylor, J. T., \& Bogdan, R. (1998). Introduction to qualitative research methods: A guidebook and resource (3rd ed.). New York, NY: John Wiley \& Sons Inc.

Vygotsky, L. S. (1978). Mind in society: The development of higher psychological processes. Cambridge, MA: Harvard University Press.

Wilson, H. (2013). The use of flipped learning in an engineering technician management course. In C. Lemckert, G. Jenkins, \& S. Lang-Lemckert (Eds.), Proceedings of the 2013 Australasian Association for Engineering Education (AAEE) Conference (pp. 1-9). Gold Coast. Retrieved from https://hdl.handle.net/10652/2775

Yelamarthi, K., \& Drake, E. (2015). A flipped first-year digital circuits course for engineering and technology students. IEEE Transactions on Education, 58(3), 179-186. https://doi.org/10.1109/TE.2014.2356174

Zhang, Y., Dang, Y., \& Amer, B. (2016). A large-scale blended and flipped class: Class design and investigation of factors influencing students' intention to learn. IEEE Transactions on Education, 59(4), 263-273. https://doi.org/10.1109/TE.2016.2535205

Corresponding author: Paul Docherty, paul.docherty@canterbury.ac.nz

Australasian Journal of Educational Technology (C) 2019.

Please cite as: Zaka, P., Fox, W. H., \& Docherty, P. D. (2019). Student perspectives of independent and collaborative learning in a flipped foundational engineering course. Australasian Journal of Educational Technology, 35(5), 79-94. https://doi.org/10.14742/ajet.3804 